\title{
New Deal Issues and the American Electorate, 1952-1988
}

\author{
John G. Geer
}

\begin{abstract}
As each presidential election passes into the history books, debate renews over the status of the New Deal Party System. This article addresses part of that debate by examining changes in the electorate's assessment of New Deal issues. Despite the vast literature on realignment, there have been few efforts to see whether issues associated with the New Deal still shape the political attitudes of the American electorate. Using the NES's openended like/dislike questions on parties and candidates from 1952 to 1988 , I show that New Deal issues remain central to the partisan attitudes of the public. These findings show that the agenda of the New Deal remains an integral part of how the American public thinks about their candidates and parties. There, of course, has been much change over the last four decades, but these results suggest, in general, that at least parts of the New Deal Party System remain intact.
\end{abstract}

It has been nearly sixty years since Franklin Roosevelt captured the U.S. presidency. In the years following his inauguration, FDR oversaw a great many changes in American politics. One of the more important changes during his reign was the emergence of the New Deal Party System. Out of the turmoil of the Great Depression and FDR's response to that calamity, the Democrats emerged as the majority party for the first time since the Civil War. The rise of the Democrats as the dominant force in national politics can be attributed, in part at least, to a set of issues that one might label "New Deal." By 1936, the Democrats were arguing, among other things, that the federal government should protect "the family and home," establish "opportunity for all the people," and aid "those overtaken by disaster." The Republicans, in contrast, opposed such action, preferring instead to rely on "the character and virtue, self-reliance, industry and thrift of the people," not "on the wisdom and power of the government." These different approaches to solving the problems of the Great Depression were instrumental in the birth of the nation's fifth party system. ${ }^{2}$

John G. Geer, Department of Political Science, Arizona State University, Tempe, Arizona 85287. 
The purpose of this article is to assess whether the public still thinks about the issues associated with the New Deal and whether the Democrats continue to benefit from the electorate's assessment of them. While we know that there has been a restructuring of the coalitions of the parties (see Petrocik, 1981, 1987; Stanley, Bianco, and Niemi, 1986; Ladd and Hadley, 1978), and that the Republicans have been dominating presidential elections over the last twenty years, we do not know very much about whether New Deal issues still structure the political thinking of the electorate.

Such information is crucial in determining the status of the New Deal Party System. While party systems can be viewed from a variety of angles, ${ }^{3}$ all previous systems have been defined by some overriding issue that dominated the political debate, like slavery in the 1850s or free silver in the 1890s. The New Deal Party System is no different. In this case, controversy arose over the proper role of government in the economic lives of the electorate. This broad controversy led the parties to struggle over a set of narrower issues that redefined the political landscape. Issues such as social security, price subsidies for farmers, protection of labor unions, and constraints on business practices all became part of the New Deal agenda. Thus, one way to assess the status of the New Deal Party System is to determine whether these kinds of issues still shape how the public thinks about the parties and candidates.

One might be tempted to claim that given the recent defeats of the Democratic nominees, there must be a significant shift in the role of New Deal issues. Otherwise, how could the Democrats have lost five of the last six presidential elections? Although such a conclusion may prove accurate, it is also hasty. The outcome of any election can turn on many issues and not always those connected with a particular party system. In fact, the minority party has great incentive to stress issues tangential to the party system. As Carmines and Stimson observe, the minority party's goal is "to upset the dominant party alignment, including the issue basis on which it has been constructed" (1989, p. 6). So in 1988 Bush ran a campaign that talked about flag factories and Willie Horton, not health care and social security. The issues Bush stressed, of course, have little connection to the New Deal, but they were probably instrumental in helping Bush secure the presidency. Consequently, New Deal issues could remain important to the public and the Democratic party could maintain a lead on these concerns, despite the outcome of recent presidential elections.

Using data from the National Election Studies (NES), I find that the issues comprising the heart and soul of the New Deal remain important to the partisan calculations of the American public and that the Democrats remain ahead of the Republicans on these matters, even during the socalled Reagan era. There has been important change in the role of New 
Deal issues since the 1950s, but the durability of these concerns is impressive. These findings do not necessarily mean that the New Deal Party System is alive and well. Clearly, the shifts in the coalitions of the parties and the recent inability of the Democrats to capture the White House indicate that important partisan change has unfolded over the last four decades. But the fact that New Deal issues continue to structure the partisan debate suggests, at minimum, that significant parts of the political agenda set in motion in the 1930 s remain intact.

To accept these various conclusions, however, one must find my definition of New Deal issues reasonable, believe that the NES's open-ended questions about the parties and the candidates accurately reflect the partisan concerns of the electorate, and believe that the method of analyzing these data is valid.

\section{NEW DEAL ISSUES}

My argument hinges, in large part, on a particular conception of what issues can be thought of as "New Deal." Disagreement over this definition will arise, since there are many ways to view New Deal issues. One might, for instance, argue that the debate over using the federal government to solve the economic ills of the nation is the issue that best symbolizes the New Deal. That view, of course, has merit. But the actual partisan disputes stemming from the New Deal often dealt with much more specific issues than just government intervention. Matters like agricultural policy, banking, and social security were all part of the vast array of concerns emerging from that turbulent era. Consequently, I shall treat New Deal issues in a way that emphasizes these narrower concerns.

The immediate question, of course, becomes: What issues constitute the New Deal? In a recent article, Stanley Kelley offers a useful definition that emphasizes these narrower concerns:

In the New Deal era, controversy swirled about a particular set of conditions, policies, interests, and ideological themes. As one would expect in a party system born in the Great Depression, economic conditions-employment, wage levels, the cost of living, the goodness or badness of the times-were in the foreground of political debate. So were certain areas of policy, among them monetary and fiscal policy, agricultural and labor policy, social security and other welfare programs, housing, power, education and health care. The era saw a politicizing of the interests of labor unions, farmers, the aged, the poor, and its rhetoric pitted the interests of "the common man," or working people, against those of big business, industry, and Wall Street. Ideological discourse put left and right, liberalism and conservatism, and radicalism and reaction in opposition to each other 
and made tests of right thinking out of orientations toward big government, states' rights, planning, governmental action to improve social conditions, and control (or interference with) private enterprise. (1988, p. 190)

These topics, ranging from labor policy to worries about big business, will be treated as New Deal issues.

While this definition has appeal, a number of criticisms may arise. To start, one may question whether this particular set of issues accurately reflects the New Deal. There is no way to satisfy everyone's view on this matter, but this definition should at least be seen as reasonable. For instance, if one examines the 1936 Democratic and Republican platforms, one will find that every topic I define as a New Deal issue was mentioned in some fashion in those documents. These two platforms provide some clue about the value of this definition, since they were the first official response by the national parties to the multitude of legislation that emerged between 1933 and 1935 .

A second possible objection is that this definition includes "too many" issues. A quick count of the issues mentioned yields over thirty different concerns. While many issues do fall under this wide umbrella, it is not clear that there are "too many." If one considers the numerous topics in a presidential campaign, New Deal issues, as defined here, comprise just a subset of these topics. For instance, matters surrounding the international arena are absent from this definition. Racial problems, crime, drugs, urban decay, and abortion also fall outside its purview. In political campaigns the candidates' personalities play a big role, yet these matters are not treated as New Deal issues. ${ }^{4}$

Another related criticism of this definition might be that some of the issues included should not be considered "New Deal." One might, for instance, argue that concerns about fiscal policy, unemployment, or inflation were probably important to citizens before the New Deal and thus are independent of it. This argument has merit if one thinks that New Deal issues should be unique to that era. But there is little reason to adopt such a position. Consider, for instance, that the alignment of the 1890s was built in large part on the economic issues surrounding the dispute over free silver and the recession of 1893. The alignment of the 1930s was also built in part around economic issues, but those concerns stemmed from efforts to overcome the Great Depression. In all likelihood, then, matters pertaining to fiscal policy or unemployment would be part of each alignment, making it reasonable to include such concerns in one's conception of both "New Deal" and "free silver" issues. Sundquist offers support for this position, arguing that in "every new alignment of the party system . . . there will be large, perhaps dominant, elements carried over from the old" (1983, p. 17). 


\section{THE EVIDENCE}

To chart changes in the public's assessment of New Deal issues, I shall rely on the NES's open-ended questions that ask respondents to state in their own words what they like and dislike about the two parties and the two presidential nominees. ${ }^{5}$ The NES provides up to five answers per respondent for each of these eight questions, allowing potentially for forty comments. ${ }^{6}$ Individuals rarely make forty comments. But they do average about eight comments each, providing a rich source of information.

These questions were first asked in 1952 and have been worded the same since then, creating an excellent opportunity to trace changes in the public's attitudes over a thirty-six-year time frame. This long-time series is particularly useful when assessing the importance and influence of the New Deal issues. While scholars disagree over the current status of the New Deal Party System, most believe it was in force during the 1950s and early 1960s. Thus, the results from the presidential elections of 1952, 1956, and 1960 provide a good benchmark from which to judge the public's response to New Deal concerns in the 1970s and 1980s. ${ }^{7}$

Another asset of the like-dislike questions is that they are open-ended. This format allows respondents to describe parties and candidates in their own words, increasing the likelihood that these individuals mention concerns that are important to them (RePass, 1971; Kelley, 1983). ${ }^{\circ}$ This aspect of the data is critical, since an issue must be salient to citizens before it can realign their partisan attitudes (Sundquist, 1983; Carmines and Stimson, 1984).

\section{METHOD}

At this point, we have the data and a definition of what issues qualify as "New Deal." The next task is to devise a way to detect changes in the importance and partisan influence of these issues over the last forty years. There are a number of possible approaches. For this paper, I shall build upon Kelley's (1983) scheme of "interpreting elections." The modifications I introduce seek to adapt that approach to the study of partisan change.

To assess the importance of New Deal issues, I shall rely on two different measures. The first measure Kelley (1983) and others have referred to as salience: the proportion of the electorate that mentions at least one New Deal issue among their responses to the open-ended questions about the parties and candidates. That information is quite useful, since we can see whether the proportion of the electorate that finds New Deal issues relevant has increased or decreased over time. In an effort to provide an additional indicator of the importance of New Deal issues, I have developed a new measure, density: the proportion of all comments that are New Deal 
in nature. This statistic is helpful, since it reports the share of the total partisan debate that can be labeled as New Deal. Thus, if there has been a shift away from the New Deal, density should decrease. Note that since the unit of analysis is the response, this measure provides no information about how many individuals made New Deal comments.

These two measures in tandem should provide a satisfactory basis for estimating the importance of New Deal issues to the public. We also need to focus on which party the public views more favorably on these matters. It is possible that New Deal issues could still be salient to the public, but they could now draw citizens into the Republican camp. To test for this possibility, I have attached partisan signs to respondents' New Deal comments. A pro-Democratic New Deal comment is either a statement telling what individuals like about the Democrats or dislike about the Republicans. The reverse is true for pro-Republican comments. Like Kelley (1983), I then weighed each comment equally and simply subtracted the Republican total from the Democratic total. ${ }^{9}$ Therefore, the measure of New Deal issues for respondents ranges from +20 , a highly Democratic score, to -20 , a highly Republican score. In practice, however, the values rarely exceed +10 or -10 .

With this estimate of respondents' feelings on New Deal issues, one can then measure whether citizens favor the Democrats or Republicans on these matters. Here I shall rely on Kelley's (1983) notion of bias-that is, the proportion of respondents who see that issue as favoring one party or candidate. ${ }^{10}$

This measure, however, only tells part of the story. If, for instance, an issue heavily favors one party (i.e., a large bias) yet is salient to only a handful of people, that issue will lack the power to forge significant partisan change among the entire electorate. Similarly, a highly salient issue that favors neither party (i.e., a bias of $50 \%$ ) would also be unable to alter the net partisan evaluation of the electorate. To generate significant partisan change (e.g., the New Deal Party System), therefore, an issue must be highly salient (e.g., the Great Depression) and must heavily favor one party (e.g., the Democrats). What we need, in other words, is to combine salience with bias.

To do so, I want to introduce the concept of net pull: the relative ability of the two parties to attract supporters on a given issue. ${ }^{11}$ The central idea here is that as an issue pulls some citizens to one party, it pushes others to the opposing side. So, for instance, while FDR's New Deal apparently brought many people into the Democratic fold, his stand on governmental activism surely drove others into the Republican camp. Thus, we need to assess the ability of each party to attract supporters on the basis of an issue and then compare those totals to get an estimate of the overall gain (or loss) for one party or the other. The formula I propose is as follows: 
net pull $=$ salience of an issue $\times($ Democratic bias on that issue Republican bias on that issue)

One way to think of net pull is the lead a particular party holds over the other on a specific issue (or set of related issues). If that lead shrinks or grows, the result provides a useful estimate of partisan change.

There is one final methodological task. Since we are interested in tracing partisan change over time, we need a way to summarize any trends that appear in the data. In an attempt to provide a systematic reading of these partisan shifts, I shall regress the election year on each of these proportions. I am not suggesting that time has caused the changes in these numbers; rather, I am providing a way to measure change over time. Without estimating the slopes and the standard errors, one must just "eyeball" the data. Norpoth and Rusk adopt a similar approach, arguing that it captures "more accurately the extent of change over time" (1982, p. 528).

\section{THE RESULTS}

Table 1 reports the change in importance of New Deal issues using the NES's open-ended questions on the parties and the candidates. If one looks only at the results for the "likes and dislikes" about the parties, it appears that the importance of New Deal issues is waning. In 1952, for instance, nearly 80 percent of respondents cited at least one New Deal issue in their assessment of the parties. Just four years later, the proportion declined to 66 - the largest drop of any four-year period. By the early 1980s, the proportion of the electorate that viewed New Deal issues as salient slipped to just slightly over 50 percent. On average, salience has declined about 2 percentage points per election. Density, on the other hand, has been quite stable over time, indicating that among all comments New Deal concerns play as big a role in the 1980s as they did in the 1950s. But the fact that there are fewer individuals making New deal comments in the 1980s, as indicated by salience, represents a significant decline in the importance of these issues. ${ }^{12}$

The answers to the open-ended questions concerning parties suggest that a shift away from the agenda of the New Deal may be underway (or has taken place). When assessing the importance of New Deal issues, however, it is also important to look at the extent to which these concerns are associated with the nominees of the parties. As Wattenberg (1990) has carefully demonstrated, the public over the last thirty-six years has come to tie issues more closely to candidates than to parties. Thus, by using data generated by comparable questions on presidential candidates, one should be able to assess more fully the importance of New Deal issues to the American public. 
TABLE 1. Importance of New Deal Issues for the Electorate, 1952-1988

\begin{tabular}{|c|c|c|c|c|c|c|c|}
\hline & \multicolumn{2}{|c|}{$\begin{array}{l}\text { Likes/Dislikes } \\
\text { for Parties }\end{array}$} & \multicolumn{2}{|c|}{$\begin{array}{l}\text { Likes/Dislikes } \\
\text { for Candidates }\end{array}$} & \multicolumn{2}{|c|}{$\begin{array}{l}\text { Likes/Dislikes } \\
\text { for Both }\end{array}$} & \multirow[b]{2}{*}{$N$} \\
\hline & Salience & Density & Salience & Density & Salience & Density & \\
\hline 1952 & 79 & 55 & 21 & 7 & 80 & 32 & 1799 \\
\hline 1956 & 66 & 47 & 27 & 9 & 71 & 26 & 1762 \\
\hline 1960 & 64 & 51 & 34 & 8 & 69 & 26 & 1932 \\
\hline 1964 & 61 & 50 & 43 & 16 & 72 & 29 & 1571 \\
\hline 1968 & 61 & 41 & 32 & 10 & 68 & 24 & 1557 \\
\hline 1972 & 53 & 46 & 49 & 20 & 68 & 31 & 1372 \\
\hline 1976 & 55 & 50 & 41 & 15 & 68 & 29 & 2870 \\
\hline 1980 & 51 & 50 & 49 & 18 & 70 & 29 & 1570 \\
\hline 1984 & 53 & 48 & 68 & 33 & 78 & 39 & 2257 \\
\hline 1988 & 60 & 51 & 44 & 22 & 69 & 35 & 2040 \\
\hline Mean & 60 & 49 & 41 & 16 & 71 & 30 & \\
\hline Slope $^{a}$ & $-2.1^{b}$ & -.2 & $3.5^{b}$ & $2.2^{b}$ & -.4 & .9 & \\
\hline S.E. & .6 & .4 & .9 & .5 & .5 & .4 & \\
\hline
\end{tabular}

Source: National Election Studies.

${ }^{a}$ The year of the survey was coded $1952=1,1956=2,1960=3$, etc. The slope, therefore, indicates the average change for each presidential election.

Note that slopes and standard errors for this table and all subsequent ones are rounded off to the first decimal place. Also, since the time series involves just ten elections, the slopes have to be larger than just twice the size of the standard error to make the .05 cutoff.

Note that to calculate the means and the regression estimates I used proportions rounded off to one decimal place. In the table, however, I have rounded up to whole numbers for the actual cell entries. This procedure is followed for all tables.

${ }^{b}$ Statistically significant at the .01 level.

The data from the public's evaluation of candidates tell a far different story from that of the electorate's assessment of parties: Namely, the importance of New Deal issues has increased since the 1950s. With regard to New Deal comments about candidates, both salience and density have risen over the thirty-six-year period. In 1956, about 27 percent of the electorate found New Deal matters salient when assessing the nominees. By 1984, the proportion soared to 68 percent. The surge in 1984 was unusual, but compared to the rest of the 1980s, or even the 1970s, candidates are still being judged more for their stands on New Deal issues than they were in the 1950s. The slope for salience confirms this observation, showing that, on average, there has been a 3 to 4 percent increase per election since 1952. In the case of density, the rise has been about threefold since the 1950s. ${ }^{13}$

This finding is important and interesting, since it is at odds with most of the previous work in this area. It would be problematic to argue, however, 
that these data about the candidates suggest that the New Deal is stronger in the 1980s than in the 1950s, especially given the results from the first two columns in Table 1 (not to mention the evidence presented by other political scientists). Nonetheless, the obvious question becomes which set of findings should one emphasize? Fortunately, the issue is not whether one set is "better" than the other in assessing partisan change. In point of fact, the best course is to combine both sets of questions into a single estimate of citizens' "partisan" calculations.

This choice stems, in part, from an underlying conception on a party system. It seems reasonable to believe that party systems structure not only how citizens evaluate parties but how they judge the candidates of those parties. If true, then candidates in the $1890 \mathrm{~s}$, for instance, would have been judged, in part, on the basis of their views on free silver. Similarly, the issue of slavery would have been an integral part of the electorate's assessment of presidential candidates in the 1850s. While we cannot be sure, such scenarios seem likely. In more recent times, the issue of social security illustrates quite well this point. To some degree, support of this program, a cornerstone of the New Deal, has served as a litmus test for presidential candidates since the 1930s. Nominees of the major parties have needed to show support for it or face electoral trouble, as Barry Goldwater might attest. Even Ronald Reagan, a frequent critic of social security in the 1970s, changed his stance on this issue for the 1980 campaign. He knew that if he did not support this safety net for the less fortunate, there could be serious electoral consequences (Drew, 1981, pp. 298, 308). Such behavior underscores the connection between the candidates and the central issues of the party system. Thus, while looking at the comments about the parties and candidates separately is instructive, it is also important to examine the combined role of New Deal comments when assessing the "partisan" evaluations of citizens.

A second and related reason for this choice is that even though each question asks explicitly about parties or candidates, there may be some conceptual slippage. That is, one cannot treat the nominees as completely distinct from the parties. Ronald Reagan, for instance, is now tied closely to how people think of the GOP (Grand Old Party). In the 1930s, FDR's flamboyant style surely became part of citizens' assessments of the Democrats. The recent efforts by the GOP to label the Democrats as the party of Jimmy Carter lends further support to this point. In short, candidates often help define the parties, just as the parties help define the candidates. ${ }^{14}$

The last two columns in Table 1 present the results when one combines the both sets of questions into a single indicator. As one can see, New Deal issues have remained remarkably stable in their importance to the public during the four decades studied. There was a noticeable drop in the sa- 
lience of New Deal issues after 1952. But since then, the salience of New Deal issues has hovered right around 70 percent. The 1984 election saw a small jump to 78 percent, but by 1988 salience returned to 69 percentjust about average. Density has also varied a bit from one campaign to another. But for both measures, the small and statistically insignificant regression slopes confirm the general sense of stability. Based on the data since 1956, there is little evidence of a decline in the importance of New Deal issues to the public. ${ }^{15}$

While the findings above show that the public continues to think about New Deal issues, these data do not reveal whether there has been any change in the electorate's assessment of parties on these matters. Carmines and Stimson $(1981,1984,1989)$, for instance, have forcefully argued that although there may not have been a shift in party systems, there still has been important partisan change affecting the balance of the two parties. Consequently, it is important to examine what, if any, inroads the GOP has made into the Democrats'standing on New Deal issues.

The findings indicate that the Republicans have made inroads in the public's partisan evaluation of New Deal issues. As Table 2 reports, the GOP has enjoyed clear gains in the public's comments about the parties. The Democrats have managed to maintain a favorable bias during the entire period, but, on average, it has slipped by about one percentage point per election. The electorate's perception of candidates on New Deal issues tells a slightly different story, depending on one's point of comparison. The Democratic bias in 1984 and 1988, for instance, was much the same as it was in 1952 and 1956. But if one, instead, compares the last two presidential elections to that of 1964, then there have been significant gains by the GOP. In 1964, LBJ netted the highest bias of any of the ten elections (71 percent), which was nearly 15 percentage points higher than Dukakis's rating. It is unclear which comparison is more useful. But it is hard to escape the fact that the Republicans have been able to forge a more positive bias in recent years.

The net pull provides the best summary of the impact of New Deal issues on the electorate's political views, since it combines salience and bias. The results, like those above, indicate that the Democrats remain the majority party on these issues, albeit a shrinking majority. From 1952 to 1964 , the average net pull for the public assessment of parties and candidates was about $25 .{ }^{16}$ From 1968 to 1988 , the Democratic advantage shrunk to just over 11. Consider, for instance, that against Carter in 1980, Reagan enjoyed as large an advantage as Johnson did over Goldwater, not due to issues such as defense and morality but die to the bread and butter issues of the New Deal. As a result, in 1980 the overall net pull favored the Republicans for the first time. The edge was slight, but compared to the 
TABLE 2. The Electorate's Assessment of Parties and Candidates on New Deal Issues, 1952-1988

\begin{tabular}{|c|c|c|c|c|c|c|}
\hline & \multicolumn{2}{|c|}{$\begin{array}{l}\text { Likes/Dislikes } \\
\text { for Parties }\end{array}$} & \multicolumn{2}{|c|}{$\begin{array}{l}\text { Likes/Dislikes } \\
\text { for Candidates }\end{array}$} & \multicolumn{2}{|c|}{$\begin{array}{l}\text { Likes/Dislikes } \\
\text { for Both }\end{array}$} \\
\hline & $\begin{array}{c}\text { Democratic } \\
\text { Bias }\end{array}$ & $\begin{array}{l}\text { Net }^{a} \\
\text { Pull }\end{array}$ & $\begin{array}{c}\text { Democratic } \\
\text { Bias }\end{array}$ & $\begin{array}{l}\text { Net } \\
\text { Pull }\end{array}$ & $\begin{array}{c}\text { Democratic } \\
\text { Bias }\end{array}$ & $\begin{array}{l}\text { Net } \\
\text { Pull }\end{array}$ \\
\hline 1952 & 66 & 26 & 56 & 2 & 64 & 23 \\
\hline 1956 & 74 & 31 & 57 & 4 & 69 & 28 \\
\hline 1960 & 67 & 21 & 63 & 9 & 65 & 21 \\
\hline 1964 & 67 & 21 & 71 & 18 & 69 & 27 \\
\hline 1968 & 60 & 12 & 55 & 3 & 58 & 10 \\
\hline 1972 & 69 & 20 & 49 & -1 & 60 & 14 \\
\hline 1976 & 68 & 19 & 66 & 13 & 67 & 23 \\
\hline 1980 & 62 & 13 & 32 & -18 & 48 & -3 \\
\hline 1984 & 60 & 11 & 54 & 5 & 57 & 11 \\
\hline 1988 & 61 & 13 & 57 & 6 & 60 & 13 \\
\hline Mean & 65 & 19 & 56 & 4 & 62 & 17 \\
\hline Slope & $-1.0^{c}$ & $-1.8^{b}$ & -1.1 & -.7 & -1.4 & $-2.0^{c}$ \\
\hline S.E. & .4 & .4 & 1.2 & 1.1 & .6 & .9 \\
\hline
\end{tabular}

Source: National Election Studies.

Note: See the text for the creation of bias and net pull.

"I computed net pull using measures of salience and bias rounded off to the first decimal place.

"Statistically significant at the .01 level.

"Statistically significant at the .05 level.

1950 s, it was quite a reversal. This GOP advantage was short-lived, however, as the Democrats bounced back in 1984 and 1988 with sizable leads on New Deal issues. ${ }^{17}$

The information in Tables 1 and 2 offers a host of interesting findings. To begin, the Democrats, despite recent gains by the Republicans, remain the favored party. Of course, one could argue that the trend favoring the GOP suggests that we are in the middle of a shift that will lead them to majority status. While possible, it is simply too early to tell. Perhaps an even more interesting finding is the differential trend in salience among the questions for parties and candidates. This result, at minimum, suggests that previous work that has focused solely on the public's assessments of the parties when assessing partisan change have missed an important piece of the puzzle. And this piece of the puzzle, when included in the analysis, shows that New Deal issues remain central to the public's partisan calculations-evidence that the nation's fifth party is not dead yet. 


\section{A CLOSER LOOK AT NEW DEAL ISSUES}

The accuracy of the conclusions presented so far hinge, in large part, on my definition of New Deal issues. While this definition is reasonable, one could worry that its breadth may cover up important patterns of change in the public's attitudes. These underlying patterns might actually lend support to the notion of a shift in the partisan agenda. For instance, the electorate may be far less supportive of the Democrats' commitment to an activist federal government in the 1980s. Or perhaps the public no longer thinks of the Democrats as the party of the working class. Such changes would indicate a restructuring of public attitudes, but my definition of New Deal issues may be obscuring it.

To test for this concern, I have developed four subcategories of New Deal issues: short-term economic conditions, government programs and policies, group-related attitudes, and ideological references (see Appendix A for the exact coding scheme). These four categories should help sort out the possibility of differential change in the public's thinking about New Deal issues. By examining short-term economic issues, for instance, one can measure change in the public's partisan response to such matters as inflation, unemployment, and taxes. References to "government programs and policies," on the other hand, tap the public's response to classic New Deal policies like social security, welfare, job programs, and health care. Group-related concerns measure whether the public still views the Democrats as the party of the poor, the aged, the unemployed, the farmers, and the working class. Finally, ideological concerns will detect any shift in the public's attitudes toward such things as liberals, conservatives, states' rights, and government activism. These four groups, in sum, should provide additional insight into the patches of this New Deal quilt.

Table 3 reports the importance of these issues to the public when describing what they like and dislike about the parties and candidates. ${ }^{15}$ Whether one looks at salience or density, these four sets of issues have remained important to the public over the thirty-six-year time frame. The only statistically significant change over time arises for references about New Deal programs and policies. And in this particular case, the importance of these issues has actually increased. The salience in 1984 and 1988, for instance, has more than doubled since 1952. Thus, one of the core components of the New Deal has actually become more salient to the public in recent years-hardly evidence consistent with the argument that there has been a drift away from the political concerns of the New Deal.

The next question concerns possible changes in the partisan bias of these issues. Table 4 tackles this matter, offering mixed support for claims of a shift toward the Republicans. For instance, short-term economic concerns 
TABLE 3. Importance of New Deal Issues for the Electorate, 1952-1988

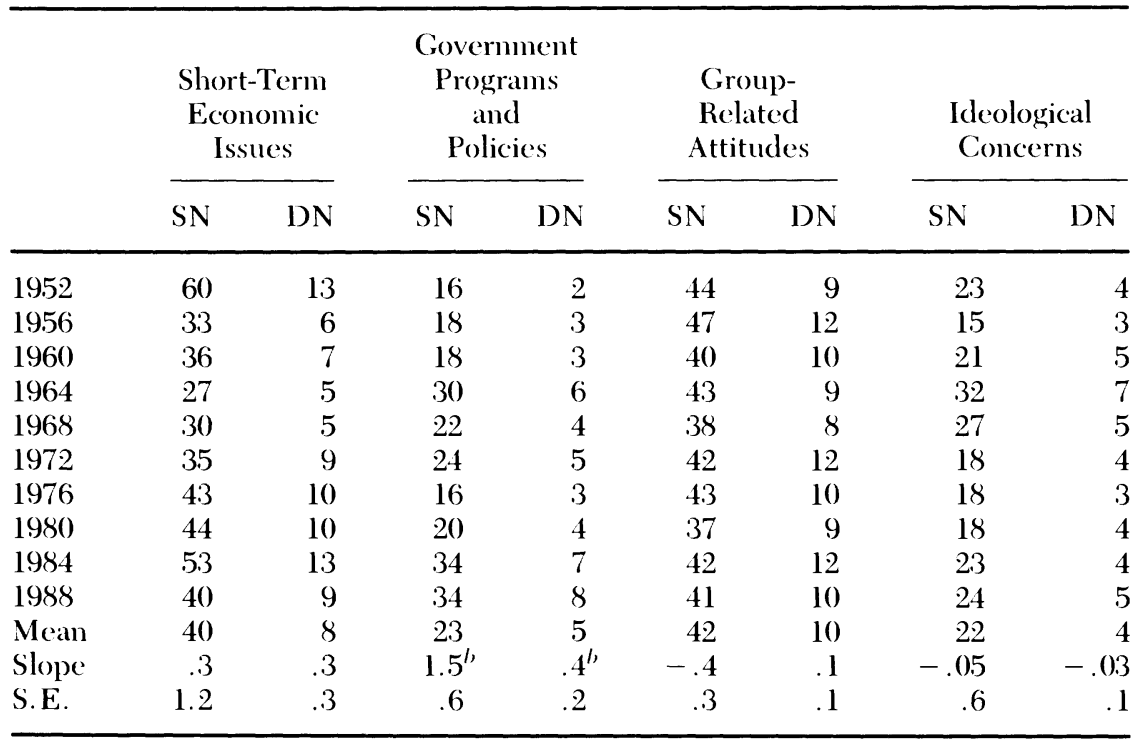

"Key: $\mathrm{SN}=$ salience; $\mathrm{DN}=$ density.

"Statistically significant at the .05 level.

now favor the GOP. In each of the last three presidential elections the Republicans have had a favorable net pull, ranging from about 22 percent in 1980 to about 8 percent in 1988. This change surely reflects a combination of Carter's economic problems in the late 1970s and Reagan's successes in the 1980s. The GOP has also made slight gains on the "ideological" front, but the increase in net pull has been less than one percentage point per election.

The other two sets of New Deal issues, in contrast, indicate continuity rather than change. For instance, during this entire period the Democrats have built huge leads in group-related concerns, suggesting that the party and its nominees continue to be favorably connected to the poor, the aged, the farmers, and the working class. This image of the Democratic party and candidates appears quite durable, since it weathered such events as Vietnam, the economic recessions of the 1970s, and the Reagan era. References to New Deal programs and policies also continue to favor the Democrats. The pattern here, however, is a bit more twisted. That is, in 1984 and 1988 the net pulls for these concerns were higher than reported in 1952 and 1956. But between 1968 and 1980, there was weakening of the Democratic 
TABLE 4. The Electorate's Assessment of Parties and Candidates on New Deal Issues, 1952-1988

\begin{tabular}{|c|c|c|c|c|c|c|c|c|}
\hline & \multicolumn{2}{|c|}{$\begin{array}{c}\text { Short-Term } \\
\text { Economic } \\
\text { Issues }\end{array}$} & \multicolumn{2}{|c|}{$\begin{array}{l}\text { Government } \\
\text { Programs } \\
\text { and } \\
\text { Policies }\end{array}$} & \multicolumn{2}{|c|}{$\begin{array}{l}\text { Group- } \\
\text { Related } \\
\text { Attitudes }\end{array}$} & \multicolumn{2}{|c|}{$\begin{array}{l}\text { Ideological } \\
\text { Concerns }\end{array}$} \\
\hline & DB & NP & $\mathrm{DB}$ & NP & $\mathrm{DB}$ & NP & $\mathrm{DB}$ & NP \\
\hline 1952 & 53 & 4 & 83 & 11 & 85 & 31 & 48 & -1 \\
\hline 1956 & 56 & 4 & 75 & 9 & 86 & 34 & 54 & 1 \\
\hline 1960 & 52 & 1 & 65 & 5 & 85 & 28 & 41 & -4 \\
\hline 1964 & 58 & 4 & 81 & 19 & 87 & 32 & 43 & -4 \\
\hline 1968 & 34 & -10 & 64 & 5 & 81 & 24 & 38 & -6 \\
\hline 1972 & 55 & 4 & 36 & -7 & 84 & 28 & 22 & -10 \\
\hline 1976 & 57 & 6 & 54 & 2 & 88 & 33 & 32 & -6 \\
\hline 1980 & 25 & -22 & 47 & -1 & 76 & 20 & 34 & -6 \\
\hline 1984 & 38 & -12 & 67 & 12 & 87 & 31 & 34 & -7 \\
\hline 1988 & 40 & -8 & 67 & 11 & 88 & 31 & 3.3 & -8 \\
\hline Mean & 47 & -3 & 64 & 7 & 85 & 29 & 38 & -5 \\
\hline Slope & -2.2 & $-1.9^{b}$ & -2.4 & -.4 & -.02 & -.3 & $-2.2^{\prime \prime}$ & $-.9^{l}$ \\
\hline S.E. & 1.1 & .9 & 1.5 & .9 & .4 & .5 & .7 & .3 \\
\hline
\end{tabular}

"Key: $\mathrm{DB}=$ democratic bias; $\mathrm{NP}=$ net pull.

${ }^{l}$ Statistically significant at the .05 level.

bias for these concerns. If one were writing in 1982, for instance, it might have been tempting to view the change as a withering of the New Deal. But additional data from 1984 and 1988 undercut such an argument.

In short, two core components of the New Deal-government programs and policies and group-related concerns-remain salient to the public and continue to favor the Democrats. Even with the popularity of Reagan in 1984 and 1988, the Democrats maintained an edge on these matters. The single biggest change over the last forty years has come on the economic front, where the public now gives the nod to the GOP. Whether this change signals the demise of the New Deal Party System is far from clear. Of all four issues, this one is probably the most fragile. That is, if the economic recession extends into the 1992 election, it could easily undo some of the recent gains by the GOP. Nonetheless, the data suggest that the public now thinks of the Republicans as the party of prosperity-a major change from the days when the GOP was thought of as the party of depression. 


\section{CONCLUSION}

What do these results suggest about the status of the New Deal Party System? Opinions in the literature range from the belief that the New Deal remains in force to that it has been replaced by a system that favors the GOP (see, for instance, Sundquist, 1983; Cavanagh and Sundquist, 1985; Miller, 1987; Shanks and Miller, 1991; Petrocik, 1981, 1987, 1989; Norpoth, 1987; Norpoth and Kagay, 1989; Beck, 1979, 1984). The findings in this paper offer, in general, more support for the former than the latter view, since New Deal issues remain about as salient to the public in the 1980s as in the 1950s and the Democrats continue to hold a lead over the Republicans on these concerns.

But within these two general conclusions, there are other important points to make about partisan change. To begin, the Democrats' lead over the Republicans on New Deal issues has been shrinking. It is far from clear whether this pattern is signaling the final decline of the Democrats. But the results are consistent with claims that the GOP is moving toward majority status. Part of the problem here is that the trend has not been monotonic. There was, for instance, a steep decline in the Democratic's edge in net pull on New Deal issues from 1964 to 1968 and 1976 to 1980. But in each case the Democrats did rebound in the following presidential election. So even if the GOP makes some important inroads in 1992, as some may think given Bush's current popularity, there is no reason to believe that the Democrats could not bounce back by 1996 .

Another point concerns the opposite trend in the salience of New Deal issues to the public. Recall that there has been a decline in the importance of New Deal issues for assessments of parties, but an increase in their importance for candidates. This pattern offers a number of interesting interpretations, some of which were addressed earlier. But one additional implication of potential significance is that these results indicate that a restructuring of the electorate's political thinking could be just around the corner. Since candidates are increasingly being judged by New Deal standards, the rhetoric of the nominees will probably have a big effect in determining the overall importance of these issues to the public. Candidates, therefore, may now be able to set the tone of the political debate for the electorate. If so, future presidential nominees could introduce a new set of issues, thereby recasting the political agenda of the American electorate. Of course, nominees like Mondale may appear in the future, breathing life into New Deal issues. But the point is that the relevance of New Deal issues to the public probably rests on a more fragile foundation than at any time since the 1950s, which could be a harbinger of significant change.

Although it is great fun to speculate about the future, the purpose of this 
paper has been to assess the public's discussion of New Deal issues over the last ten presidential elections. Given that objective, one conclusion is clear: The issues forged in the 1930s continue to be important to the electorate even fifty-five years after FDR launched the New Deal. There has been important change during the thirty-six years under study, but the durability of New Deal issues is remarkable. Moreover, the longevity of the Democratic edge on these matters is also surprising. Public opinion, in short, appears quite stubborn. Perhaps the Republicans will be able to build on their successes in the 1980s, allowing them to usher in a new set of issues that restructures the political debate. But, at this point, it appears that the New Deal will continue to be an integral part of the public's thinking well into the 1990s, suggesting that claims of a "realignment" are probably overstated and that at least parts of the nation's fifth party system remains intact.

\section{APPENDIX A: CODING OF THE OPEN-ENDED COMMENTS}

Below I list the actual codes that were treated as "New Deal" for the like/dislike questions on parties and candidates. I shall, however, present only the scheme for the 1984 survey. This year is representative of the other studies, providing the reader with a sense of the exact codes used. The other years are available upon request. One can also see Kelley (1983) for a very similar coding scheme for New Deal issues.

The "New Deal" codes for the like-dislike questions are: $7,162-165,531-536$, $605,606,805-828,833,834,837,838,910-916,920-945,952-961,1001-1003$, $1007-1009$, 1025-1027, 1201, 1202, 1205-1210, 1215, 1216, 1219-1222, 1233, 1234.

Below are the codes for the four subcategories of the New Deal issues:

Short-term economic concerns: 605, 606, 901, 926-941.

Government programs and policies: 905-916, 920-925, 942-945, 952, 959, 960, 961, 1001-1003, 107-1009, 1025-1027.

Group-related attitudes: $953-958,1201,1202,1205-1210,1215,1216,1219-$ 1222, 1233, 1234.

Ideological concerns: $162-165,531-536,805,812,816,818-828$.

Acknowledgments: I thank Dick Brody, Pat Crittenden, Charles Franklin, Rick Herrera, and Pet Kenney for helpful suggestions on earlier drafts of this manuscript. A special note of thanks goes to Warren Miller, who made numerous useful comments. An earlier version of this article was delivered at the 1989 MWPSA meetings in Chicago. The data used here were made available by the ICPSR. The author bears sole responsibility for the interpretations presented here. 


\section{NOTES}

1. These passages are taken from the 1936 Democratic and Republican platforms (see Johnson and Porter, 1973, pp. 360, 370).

2. This brief account does not, of course, do justice to the many forces that set the New Deal Party System in motion. But the basic point here is consistent with some of the best work on partisan change (see Clubb, Flanigan, and Zingale, 1980; Sundquist, 1983; and Carmines and Stimson, 1989).

3. There has been much disagreement between scholars over what constitutes a change in party systems or what political scientists commonly refer to as a "realignment." Some scholars contend that a shift in party systems occurs when there is an enduring change in the share of support the parties receive in elections (Key, 1955; Burnham, 1970; Clubb et al., 1980). An alternative conception stresses the coalitional underpinnings of the parties, holding that a new partisan arrangement arises when these coalitions undergo lasting change (Petrocik, 1981, 1987; Beck, 1982). The final perspective claims that party systems emerge when new issues arise that divide the nation and the parties, generating significant and enduring partisan change among the electorate (Sundquist, 1983; Carmines and Stimson, 1989). I do not comment directly on that debate, except to argue that one thing party systems are associated with is a set of issues that defined the political debate of the era.

4. To support the argument that this definition is not "too" broad, one can look at the NES's coding scheme for the open-ended questions asking respondents what they like and dislike about the parties and candidates. The NES provides over 500 different codes to represent the many statements citizens make in response to these questions. Using Kelley's definition of New Deal issues as a guide, about 20 percent of all codes in 1984 were labeled "New Deal." It is unclear, of course, whether this proportion is large or small, but at least a good many non-New Deal concerns exist. Actually, the share of New Deal comments seems reasonable, given that any set of issues associated with a party system should dominate the political debate and thus is likely to comprise a large part of it.

5. Specifically, the NES poses the following questions to respondents:

Is there anything in particular about (the candidate's name) that might make you want to vote for him?

Is there anything in particular about (the candidate's name) that might make you want to vote against him?

Is there anything in particular you like about the (Democratic or Republican) party?

Is there anything in particular you don't like about the (Democratic or Republican) party?

6. In 1972, the NES released only three responses to the open-ended questions. In another version of the data, however, all five comments were included. I want to thank Michael Kagay for making this latter version available to me.

7. The definition of New Deal issues I presented above served as the guide for what comments to include and what to exclude. Appendix A presents the specific coding scheme.

8. Eric Smith has recently marshaled an impressive critique of the like/dislike questions, arguing, among other things, that the responses "do not reveal fundamental attitudes" but instead measure "superficial" concerns (1989, pp. 84, 87). This argument raises serious doubts about the usefulness of these data to study partisan change. Smith's (1989) distinction, however, between "fundamental" and "superficial" attitudes is problematic. He assumes that new information can generate only superficial attitudes. Such an assumption is unreasonable, since surely some recently learned information will be important to citi- 
zens. Geer (1991) has presented some experimental evidence consistent with this point, suggesting that responses to open-ended questions can in fact tap salient attitudes.

Smith (1989), however, is correct in arguing that the ebb and flow of a campaign will have some influence on the content of responses to open-ended questions. But this finding should not be a worry, since, as noted above, some information available in campaigns is likely to be salient to voters. Moreover, if an issue like abortion dominates a particular election, the responses of some citizens to the open-ended questions may reflect it. But if concerns about abortion are indeed "short-term," then one should see a decline in the importance of this issue for the next election. Thus, by examining a series of elections, one should be better able to sort out such temporary effects. But if the change persists over a number of elections, it would indicate a shift in the political debate and hence comment on the relevance of those issues to the public.

9. One may voice concern about weighting each comment equally. It is possible, for instance, that the first comment is more important to respondents, suggesting some sort of weighting scheme may be in order. While such a view is quite reasonable, Kagay (1980) provides a statistical defense of this assumption. See also Kelley for additional justifications of it (1983), pp. 13-15, 227-238).

10. Note that citizens who see the issue as favoring neither party are not represented in this measure. Therefore, if the Democratic bias is 55 percent, the Republican bias is 45 percent.

11. This concept builds on Kelley's (1983) notion of "pull" that measures whether an issue favors a particular party. Although that measure is useful for interpreting elections, it does not tell us how the opposing party fared on that issue. To assess partisan change, we need to know the pull of both parties on an issue; hence the notion of net pull.

12. This trend, of course, reflects the increase in the number of people who make no comments at all about the parties (see Sniderman, Brody, Seigel, and Tannenbaum, 1982; Wattenberg, 1990). One can interpret this rise in what Sniderman and colleagues call "indifferents" a number of ways. For the purpose of this article, I shall treat this change as a sign of what some have called "dealignment."

13. An additional way to disaggregate these results is to examine shifts within each question. So, what does the trend look like for the public's "likes of the Democratic party"? or "dislikes of the Republican candidate"? etc. For each of the eight questions, the same pattern found in Table 1 appears. That is, among the four questions about the two nominees, New Deal issues have become more salient. For the items concerning the parties, the importance of concerns about the New Deal have declined. There is more instability in these patterns, but the results lend additional support to the evidence presented above.

14. One can test crudely this notion of overlap by looking at certain responses to the openended questions. Specifically, do respondents talk about party leaders when discussing the parties? And do citizens mention the party when assessing the candidates? In both cases, the answer is yes. Using data from 1988, 36 percent of respondents made a partisan connection with one of the candidates (open-ended codes 500-597). At the same time, 11 percent of the sample mentioned a party leader when discussing what they liked and disliked about the parties (open-ended codes 1-97).

15. One might wonder how the salience of New Deal issues compares to other sets of concerns. To some extent, density provides a test for whether other issues have eroded the relative importance of New Deal issues. But still other concerns could be increasing in salience to the electorate. To consider this possibility, I looked at mentions about foreign policy and the so-called "social issue." In both cases, no such patterns arose. I also examined whether "personality" concerns have increased among the questions about the candi- 
dates. With the rise of "candidate-centered" campaigns, one might think that citizens make more comments about the personal characteristics of the candidates in the 1980s than the 1950s. Again, the data do not support such a hypothesis. These additional analyses lend further support to the conclusions presented so far.

16. Just as a point of comparison, a net pull of 25 percent is quite large. Consider, for example, for an issue that is highly salient (let us assume $85 \%$ ) and that heavily favors a party (65\% to $35 \%$ ), the net pull is about 26 percent.

17. A good deal of scholarship has focused on shifts in the coalitional underpinnings of the two parties. An advocate of that approach might argue that the importance and influence of New Deal issues may vary across different segments of the electorate. Thus, by not examining relevant coalitional groups in the electorate, one may miss significant patterns of change in the salience and partisan influence of New Deal issues.

To explore these potentially differential patterns of change, I examined how blacks, white southerners, members of union households, white northern Protestants, Catholics, and first-time voters responded to New Deal issues. In each case, New Deal issues remained salient to these different groups. There were, however, some significant changes in the partisan bias of these issues for a few groups. The white south, for instance, now views the GOP favorably on New Deal issues. Blacks, on the other hand, increased their support for the Democrats on New Deal issues. All in all, the data support the work of other scholars that there has been a restructuring of coalitions of the parties (see Petrocik, 1981, 1987; Ladd and Hadley, 1978; Stanley, 1987; Black and Black, 1987; Axelrod, 1986; Stanley et al., 1986). These data are available upon request.

18. I have not reported the attitudes of the public separately for parties and candidates. This decision stems, for the most part, from my earlier argument that a useful way to assess partisan change was to combine both sets of questions. But an additional benefit of this decision is that the paper is kept within a manageable size. For those interested, the patterns are much like those found in Tables 1 and 2. These separate analyses are available upon request.

\section{REFERENCES}

Axelrod, Robert (1986). Presidential election coalitions in 1984. American Political Science Review 80:281-284.

$\rightarrow$ Beck, Paul Allen (1979). The electoral cycle and patterns of American politics. British Journal of Political Science 9:129-156.

Beck, Paul Allen (1982). Realignment begins? American Politics Quarterly 10:421438.

Beck, Paul Allen (1984). The dealignment era in America. In Russell J. Dalton, Scott C. Flanigan, and Paul Allen Beck (eds.), Electoral Change in Advanced Industrial Democracies. Princeton, NJ: Princeton University Press.

Black, Earl, and Merle Black (1987). Politics and Society in the South. Cambridge, MA: Harvard University Press.

Burnham, Walter Dean (1970). Critical Elections and the Mainsprings of American Politics. New York, NY: Norton.

Carmines, Edward G., and James A. Stimson (1981). Issue evolution, population replacement and normal partisan change. American Political Science Review 75:107-118.

Carmines, Edward G., and James A. Stimson (1984). The dynamics of issue evolution: The United States. In Russell J. Dalton, Scott C. Flanigan, and Paul Allen 
Beck (eds.), Electoral Change in Advanced Industrial Democracies. Princeton, NJ: Princeton University Press.

Carmines, Edward G., and James A. Stimson (1989). Issue Evolution. Princeton, NJ: Princeton University Press.

Cavanagh, Thomas, and James Sundquist (1985). The new two-party system. In John E. Chubb and Paul E. Peterson (eds.), The New Direction of American Politics. Washington, DC: Brookings Institution.

Clubb, Jerome M., William H. Flanigan, and Nancy H. Zingale (1980). Partisan Realignment. Beverly Hills, CA: Sage Publications.

Drew, Elizabeth (1981). Portrait of an Election. New York: Simon and Schuster.

$\rightarrow$ Geer, John G. (1991). Do open-ended questions measure "salient" issues? Public Opinion Quarterly 55:360-370.

Johnson, Donald Bruce, and Kirk Porter (1973). National Party Platforms, 18401972. Urbana, IL: University of Illinois Press.

Kagay, Michael (1980). On two models of voter decision making: Stokes' six components and the Kelley-Mirer rule. Photocopy, Princeton University.

Kelley, Stanley, Jr. (1983). Interpreting Elections. Princeton, NJ: Princeton University Press.

Kelley, Stanley, Jr. (1988). Democracy and the New Deal Party System. In Amy Guttman (ed.), Democracy and the Welfare State. Princeton, NJ: Princeton University Press.

$\rightarrow$ Key, V. O. (1955). A theory of critical elections. Journal of Politics 17:3-18.

Ladd, Everett Carll, and Charles D. Hadley (1978). Transformations of the Party System, 2nd ed. New York: Norton.

Miller, Warren E. (1987). Party identification re-examined: The Reagan era. In Where's the Party? Washington, DC: Center for National Policy.

$\rightarrow$ Norpoth, Helmut (1987). Under way and here to stay: Party realignment in the 1980s? Public Opinion Quarterly 51:376-391.

Norpoth, Helmut, and Michael Kagay (1989). Another eight years of Republican rule and still no partisan realignment? Paper presented at the APSA conference in Atlanta.

$\rightarrow$ Norpoth, Helmut, and Jerrold Rusk (1982). Partisan dealignment in the American electorate: Itemizing the deductions since 1964. American Political Science Review 76:522-537.

Petrocik, John R. (1981). Party Coalitions. Chicago: IL: University of Chicago Press.

Petrocik, John R. (1987). Realignment: The South, New Party coalitions and the elections of 1984 and 1986. In Where's the Party? Washington, DC: Center for National Policy.

Petrocik, John R. (1989). Issues and agendas: Electoral coalitions in the 1988 election. Paper presented at the APSA conference in Atlanta.

$\rightarrow$ RePass, David E. (1971). Issue salience and party choice. American Political Science Review 65:389-400.

Shanks, Merrill J., and Warren E. Miller (1991). Partisanship, policy and performance: The Reagan legacy in the 1988 election. British Journal of Political Science 21:129-197.

Smith, Eric, R. A. N. (1989). The UnChanging American Voter. Berkeley, CA: University of California Press.

Sniderman, Paul M., Richard A. Brody, Jonathan W. Siegel, and Percy H. Tannenbaum (1982). Evaluative bias and issue proximity. Political Behavior 4:115-131. 
Stanley, Harold W. (1987). Southern partisan changes: Dealignment, realignment, or both? Journal of Politics 50:64-88.

$\rightarrow$ Stanley, Harold W., and William Bianco, and Richard G. Niemi (1986). Partisanship and group support over time: A multivariate analysis. American Political Science Review 80:969-976.

Sundquist, James L. (1983). Dynamics of the Party System. Washington, DC: Brookings Institution.

Wattenberg, Martin P. (1990). The Decline of American Political Parties, 3rd ed. Cambridge, MA: Harvard University Press. 